\title{
The influence of online reviews on word of mouth behavior through consumer purchase intention in e-commerce
}

Le, Khoa Huan

Director of International Training Center, Saigon University, Vietnam (lekhoahuan@sgu.edu.vn)

Luong, Duy Binh

Department of Business Administration, Saigon University, Vietnam (duybinh0106@yahoo.com)

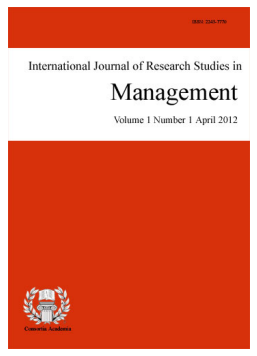

ISSN: $2243-7770$ Online ISSN: 2243-7789

OPEN ACCESS

\begin{abstract}
In online settings, user-generated online consumer reviews, one form of electronic word of mouth are considered as not only exogenous factor affecting product sales but also endogenous factors that are affected by consumer behavior. This study identifies effects of online reviews on consumer decision-making processes and how online reviews motivate consumers to make word of mouth behavior about the product through mediating effect of consumer purchase intention. The data is randomly collected from 312 Vietnamese online shoppers who had experienced Amazon website to reach the online reviews. By using tests of structural equation modeling, the findings reveal that online reviews in terms of source credibility, number of online reviews and valence of online reviews affect consumer purchase intention and also positively affect WOM behavior through mediating variable.
\end{abstract}

Keywords: source credibility; online review; purchase intention; word of mouth; e-commerce 


\section{The influence of online reviews on word of mouth behavior through consumer purchase intention in e-commerce}

\section{Introduction}

In online environment, consumers from all over the world flock to the Internet to search for information about product/service which is an important stage in their decision making process (Wu \& Lin, 2017); and moreover, the global rapid expansion of social media platforms and usage brings opportunities and challenges of accessing diversified information sources (Lin et al., 2016). User-generated consumer reviews which are often viewed as online word of mouth (WOM) represent an information source for individuals who seek for information online. The features of Internet communication technology facilitate user-generated content being spread out or transmitted among virtual communities (Duffy and Thorson, 2008). Most e-commerce websites actively utilize online review system to provide their consumers' user ratings (review valence), number of reviews, review expertise, and many others. for these electronic words of mouth (eWOM) consumer reviews. Online reviews have been even indicated to influence consumer behavior more than brand and price (ShareThis, 2014). However, the appearance of more and poorer quality messages and misinformation resulting from the increasing number of online shoppers and ease of participation of online reviewers may cause users and companies difficulties in organizing and controlling related information, especially under conditions of potential risk and uncertain (Lachlan, Spence, Lin, Del Greco, \& Najarian, 2014 \& Ratzan, 2011). Thus, it is critical to explore how online reviews may cause consumer purchase intentions in another context. In addition, online eWOM is not only a determinant of but also an outcome of product sales (Lee \& Choeh, 2017). But most existing studies have focused on researching the eWOM effect, rarely on consumers' WOM behavior. This study aims to fulfill this gap.

Shopping online is continuously becoming more popular in Vietnam, where 30 percent of the population will be buying goods and services over the Internet by 2020, according to the Vietnam E-commerce and Information Technology Agency. And it is announced that Vietnamese consumers prefer making online purchases on international e-commerce websites such as Amazon, eBay rather than domestic ones due to their beliefs of the global reputation and credibility (VnExpress, 2017). The most percentage of online purchases comes from an online-only retailing platform such as Amazon, Lazada; followed by the website of a specific retailing shop or manufacturer or brand (KPMG, 2017). Overall, online information and reviews are useful sources that enable shoppers to trust to consider before making any purchases (KPMG, 2017).

Among e-commerce websites, Amazon is known as one of the first sites in which consumers are able to post their reviews related to the product/service (Mudambi \& Schuff, 2010). And it includes most completely the features that helpfully show up various reviews of the product/service by different individuals (Sunder, Oeldorf-Hirsch, \& Xu, 2008). For example, some information regards to user data such as user ratings, number of reviews and the ability for registered users to set up a personal profile containing helpful indicators. In other words, e-commerce websites such as Amazon enable users to engage in a valuable feedback system by providing future buyers with a window into a seller's past and ability to share their own opinions on the product page; and this is considered an effective tool in boosting sales. For example, Chevalier and Mayzlin (2006) found a positive relationship between consumer reviews on Amazon and book sales. Other e-retailer shops even collect and purchase consumer reviews on big e-commerce websites in order to grab their consumers' attraction to the product/service (Mudambi \& Schuff, 2010). Therefore, it is suggested that both eWOM effect and WOM behavior is beneficial to every e-commerce retailer. Moreover, in the context of upcoming Amazon into Vietnam (Keyes, 2018), this is a timely empirical research about the effects of online reviews toward Vietnamese consumers.

Hence, by incorporating the examination of online review and reviewer related factors, we could better 
understand consumer response toward product in a digital marketing environment. This study will identify effects of online reviews (e.g. Source credibility, number of online reviews, and valence of online reviews) on consumer decision-making processes and how online reviews motivate consumers to make WOM behavior about the product through mediating effect of consumer purchase intention. It is anticipated that study findings will advance a more comprehensive understanding of online reviews associated with online shopping in a digital technology environment. Study results are also expected to benefit digital marketing research on eWOM effect which generates WOM behavior.

\section{Literature Review}

\subsection{Source credibility}

Source credibility is obtained from reviewers' characteristics such as background and self-description (Hong, $\mathrm{Xu}$, Wang, \& Fan, 2017). It is defined as source credibility rather than the content of online reviews on which consumers have perceptions (Zhang, Zhao, Cheung, \& Lee, 2014). In other words, it represents the perceived proficiency and reliability of online review sources related to product/service (Pornpitakpan, 2004). Online reviews might be posted by unknown individuals, peers or specialists (Lee, Park, \& Han, 2008). Online information is evaluated to be more helpful and effective to consumer attitudes and purchase intentions toward product/service when it is created by experts rather than non-experts "expertise is described as the extent to which the source is perceived as being capable of providing correct information and induce persuasion" (Liu \& Park, 2015). Therefore, on most of the e-commerce websites, users are able to evaluate others' opinions based on the review quality; the number of helpful votes and contribution frequency which is shown at every register user's personal profile created on the pages (Zhang et al., 2014).

On Amazon site, the factors such as helpful votes, number of reviews regarding to the reviewers' profiles that has been authored before signal a reviewer's reputation and expertise. Then high-quality reviews resulting from credible indicators are expected to provide reliable and useful information that helps consumers learn more about products or services and enhance their decision-making. Existing research shows that source credibility is significantly important when consumers adopt online information (Zhang \& Watts, 2008) as well as other users' expertise also crucially influence individuals' decision making (White, 2005). From this perspective, in order to be consistent with the findings of Zhang et al. (2014) and Zhao, Wang, Guo, and Law (2014) that consumers are more likely to purchase the product/service if they find its online reviews are from credible ones. Therefore, the following hypothesis is provided:

H1: Source credibility of online reviews positively affects purchase intention.

\subsection{Number of online reviews}

Number of reviews refers to the sum of interactive messages containing individuals' assessment of product/service (Liu, 2006). In online settings, number of reviews measures the total amount of opinions that are posted and discussed in virtual communities by online consumers who have had experiences with the product/service (Davis \& Khazanchi, 2008). Regardless of the fact that the review itself is positive or negative, it is found that online consumers tend to pay more attention to the product/service in respect of a higher number of reviews; thereby it helps enhance consumers' perceptions (Davis \& Khazanchi, 2008). And it also indicates the level of conformity between online consumers (Elliott, 2002). Chevalier and Mayzlin (2006) have shown that the higher number of reviews regarding to a specific book is, the higher sales of that one increase on the e-commerce site. Similarly, the increasing number of reviews helps enhance consumer preference and buying intention (Vogel, Bohner, \& Wanke, 2014). In addition, it also plays a role in boosting the inherent effect of review valence on consumer buying intention (Tsao, Hsieh, Shih, \& Lin, 2005). However, a large number of reviews may cause a negative effect of information overload and high search cost on online consumers (Siering, Muntermann, \& Rajagopalan, 2018) and the number of online reviews alone has no significant impact on book sales in 
Le, K. H., \& Luong, D. B.

e-commerce by itself (Davis \& Khazanchi, 2008). Underlying this asymmetry, it is expected in this research that if consumers perceive a high quantity of reviews for a given product or service, then he/she is more likely to purchase it:

$\mathrm{H} 2$ : Number of online reviews positively affects purchase intention.

\subsection{Valence of online reviews}

Online reviews are usually associated with a rating (on a scale of 1-5), indicating reviewers' assessment of the products or services used. Typically, a 5-rating suggests an extremely positive review; a 1-rating indicates an extremely negative review. Valence of online reviews together with the content of reviews play a significant role toward consumers' evaluation (Racherla \& Friske, 2012). The findings of studies regarding to an association between online review ratings and consumer behavior can be presented in relation to different arguments. The more positive (negative) the valence of a review is, the more (less) likely people are to purchase the reviewed product/service (Willemsen, Neijens, Bronner, \& Ridder, 2011); Gavilan, Avello, and Martinez-Navarro (2018) argued that negative reviews have a greater effect on consumers and expand faster than positive ones (Hart et al., 1990), which is in contrast to the findings of Tsao et al. (2015) and Zhao et al. (2014) that positive reviews are more effective and persuasive in improving consumer buying intention than negative reviews. They lead to the inconsistent effect of review valence, and so far the impacts of them have been continuously researched and compared for a better strategy. Therefore, the following hypotheses are formulated:

H3: Positive online reviews positively affect purchase intention.

H4: Negative online reviews negatively affect purchase intention.

\subsection{Word-of-mouth behavior}

Online product reviews generated by users is one form of eWOM which has become an important information source for consumer purchase decision making (Zou, Yu, \& Hao, 2011). Most previous literature considered eWOM as an exogenous factor that affects product sales which reate one kind of WOM effect but ignore the fact that eWOM is affected by product sales and therefore is endogenously playing the role of WOM behavior. Therefore, online eWOM is not only a determinant but also an outcome of product sales (Lee \& Choeh, 2017). Due to self-enhancement and self-esteem, consumers tend to generate positive comments about the product/service when they are satisfied with their decisions by conforming to the communities' opinions (Sundaram, Mitra, \& Webster, 1998; Wangenheim \& Bayon, 2003). On the contrary, negative comments are distributed when consumers are not satisfied, and they are motivated to give low ratings (Lee \& Choeh., 2017). The existing studies have proved that the purchase intention positively influences the WOM behavior of consumers (Wirtz \& Chew, 2002; Sichtmann, 2007). Therefore, the following hypothesis in this study is provided:

H5: Purchase intention significantly affects WOM behavior.

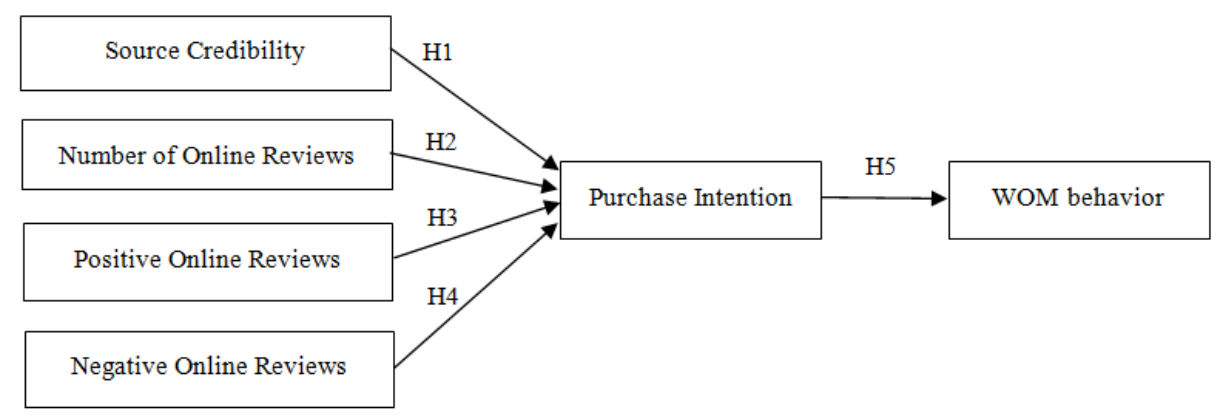

Figure 1. Proposed Model 


\section{Methodology}

\subsection{Measurement}

The survey in this study was developed based on previous studies, (Sichtmann, 2007; Zhang et al., 2014; Zhao et al., 2014; Kunja \& GVRK, 2017) after being checked and edited, it consists of six parts: Source credibility; Number of online reviews; Positive online reviews; Negative online reviews; Purchase intention; WOM behavior and demographic information. All items were measured on a five-point Likert scale, ranging from "strongly disagree" (1) to "strongly agree" (5).

\subsection{Data collection and analyses}

This study used snowball sampling method to collect data. The questionnaire was prepared in English and then translated to Vietnamese and distributed to our target respondents who had accessed and read review on Amazon website. Of the 312 potential respondents we approached, 300 available questionnaires were obtained, resulting in a response rate of $96 \%$. The data collected was analyzed by using SPSS and AMOS software to test the reliability and validity of this proposed model. SPSS software also uses to test descriptive statistics while AMOS uses to examine linear relationships among latent (unobserved) variables and manifest (observed) variables by tests of SEM.

\section{Results}

\subsection{Description of Sample}

Of a total sample of 300 respondents, 52 percent (156) were male and 48 percent (144) were female. The majority ages of respondents were 18-24 years old (46.7\%), 25-30 (39\%), and 31-40 (14.3\%). The monthly income classification was mostly distributed among the $\$ 251-\$ 400(42.3 \%)$, followed by $\$ 100-\$ 250(21.7 \%)$, $\$ 401-\$ 550$ (24\%) and more than $\$ 550(12 \%)$. The majority of respondents' education was bachelor degree $(64 \%)$, followed by master degree $(28.3 \%) .49 .3 \%$ of respondents had more four experience years of online shopping. Descriptive statistics are showed in table 1.

\section{Table 1}

Demographics information of respondents

\begin{tabular}{|c|c|c|c|}
\hline \multicolumn{2}{|c|}{ Characteristic } & Frequency & Percent \\
\hline \multirow{2}{*}{ Gender } & Male & 156 & 52 \\
\hline & Female & 144 & 48 \\
\hline \multirow{3}{*}{ Age } & $18-24$ & 140 & 46.7 \\
\hline & $25-30$ & 117 & 39 \\
\hline & $31-40$ & 43 & 14.3 \\
\hline \multirow{4}{*}{ Occupation } & Student & 131 & 43.7 \\
\hline & Officer & 123 & 41 \\
\hline & Businessman & 30 & 10 \\
\hline & Others & 16 & 5.3 \\
\hline \multirow{4}{*}{ Monthly income } & $\$ 100-\$ 250$ & 65 & 21.7 \\
\hline & $\$ 251-\$ 400$ & 127 & 42.3 \\
\hline & $\$ 401-\$ 550$ & 72 & 24 \\
\hline & $>\$ 550$ & 36 & 12 \\
\hline \multirow{3}{*}{ Education } & Bachelor & 192 & 64 \\
\hline & Master & 85 & 28.3 \\
\hline & $\mathrm{PhD}$ & 23 & 7.7 \\
\hline \multirow{3}{*}{ Experience online shopping } & $<3$ years & 50 & 16.7 \\
\hline & 4 years & 102 & 34 \\
\hline & $>4$ years & 148 & 49.3 \\
\hline
\end{tabular}


Le, K. H., \& Luong, D. B.

\subsection{Measurement model}

Table 2 showed the descriptive statistics and the Cronbach's $\alpha$ (alpha) coefficient of this study. The Cronbach's $\alpha$ was calculated to test the reliability of the questionnaire and the Cronbach's $\alpha$ coefficient of total 22 items in this study is 0.859. Hair, Black, Babin, and Anderson (2010) indicated that if the Cronbach's $\alpha$ is more than 0.7, an item is valid. Thus, it means that the reliability of measurement of the study is high and the questionnaire has a high internal consistency. Besides, the Cronbach's $\alpha$ coefficients of all groups are greater than 0.7 signifies. It means that the measurement of this study of all items is high in reliability.

Table 2

Reliability Analysis $(\alpha=.859)$

\begin{tabular}{lc}
\hline \multicolumn{1}{c}{ Constructs } & Cronbach's $\alpha$ \\
\hline Source credibility & .883 \\
Number of online reviews & .888 \\
Positive online reviews & .751 \\
Negative online reviews & .830 \\
Purchase intention & .743 \\
WOM behavior & .713 \\
\hline
\end{tabular}

Validity includes convergent validity and discriminant validity. Convergent validity measures whether items effectively reflect the corresponding construct, whereas discriminant validity measures whether two factors are statistically different. Table 3 listed the standardized item loadings, the average variance extracted (AVE), composite reliability (CR), Mean.

All factor loadings in the current work ranged from .646 to .843, which indicated that the measurement and assessment criteria exhibited excellent convergent validity (Hair et al., 2010). Fornell and Larcker (1981) recommended the value of AVE greater than 0.5 and the CR should be greater than .70 to reach the sufficient level of convergent validity. The AVE value for each construct was above .50, indicating convergent validity. The CR ranged from .716 to .889 , hence acceptable. To assess discriminant validity, the square root of the AVE for each construct was compared to the inter construct correlation (Fornell \& Larcker, 1981). The results revealed that the measurement model supported the reliability and validity of the constructs proposed in the model.

Table 3

Descriptive statistics of constructs

\begin{tabular}{lccc}
\hline \multicolumn{1}{c}{ Constructs } & Item & Standardized Loading & Mean \\
\hline \multirow{2}{*}{ Source credibility } & A1 & .770 & 3.89 \\
$(\mathrm{CR}=.883, \mathrm{AVE}=.655)$ & $\mathrm{A} 2$ & .825 & 3.80 \\
& $\mathrm{~A} 3$ & .843 & 3.80 \\
& $\mathrm{~A} 4$ & .796 & 3.83 \\
\hline & $\mathrm{B} 1$ & .703 & 3.65 \\
Number of online reviews & $\mathrm{B} 2$ & .742 & 3.72 \\
$(\mathrm{CR}=.889, \mathrm{AVE}=.572)$ & $\mathrm{B} 3$ & .814 & 3.72 \\
& $\mathrm{~B} 4$ & .811 & 3.85 \\
& $\mathrm{~B} 5$ & .727 & 3.62 \\
\hline Positive online reviews & $\mathrm{B} 6$ & .735 & 3.93 \\
$(\mathrm{CR}=.753, \mathrm{AVE}=.506)$ & $\mathrm{C} 1$ & .788 & 3.11 \\
& $\mathrm{C} 2$ & .646 & 3.13 \\
Negative online reviews & $\mathrm{C} 3$ & .693 & 3.16 \\
$(\mathrm{CR}=.839, \mathrm{AVE}=.554)$ & $\mathrm{D} 1$ & .800 & 3.27 \\
& $\mathrm{D} 2$ & .777 & 3.16 \\
Purchase intention & $\mathrm{D} 3$ & .643 & 3.06 \\
$(\mathrm{CR}=.753, \mathrm{AVE}=.502)$ & $\mathrm{D} 4$ & .748 & 3.36 \\
\hline WOM behavior & E1 & .740 & 3.58 \\
$(\mathrm{CR}=.716$, AVE $=.559)$ & $\mathrm{E} 2$ & .677 & 3.68 \\
\hline
\end{tabular}

6 Consortia Academia Publishing 


\subsection{Structural model}

SEM was used to analyze the structural relationships and associated hypotheses. Using Amos 20.0 software, the results indicated that the overall model fit, as indicated by the $\mathrm{X}^{2}$ statistic $\left(\mathrm{X}^{2}=401.532 \mathrm{df}=194, p<.01\right)$, within the acceptable range for the sample $\left(\mathrm{X}^{2} / \mathrm{df}=2.070\right)$. For the structural model, the goodness of fit index (GFI = 0.896), the comparative fit index $(\mathrm{NFI}=0.891)$, Tucker-Lewis index (TLI $=0.915)$ and comparative fit index $(\mathrm{CFI}=0.928)$ values were satisfactory. Finally, the root mean square error of approximation $(\mathrm{RMSEA}=$ 0.063 , with values $<0.08$ indicating good fit), indicated that the structural model was a reasonable fit. Figure 1 showed the results of confirmatory factor analysis.

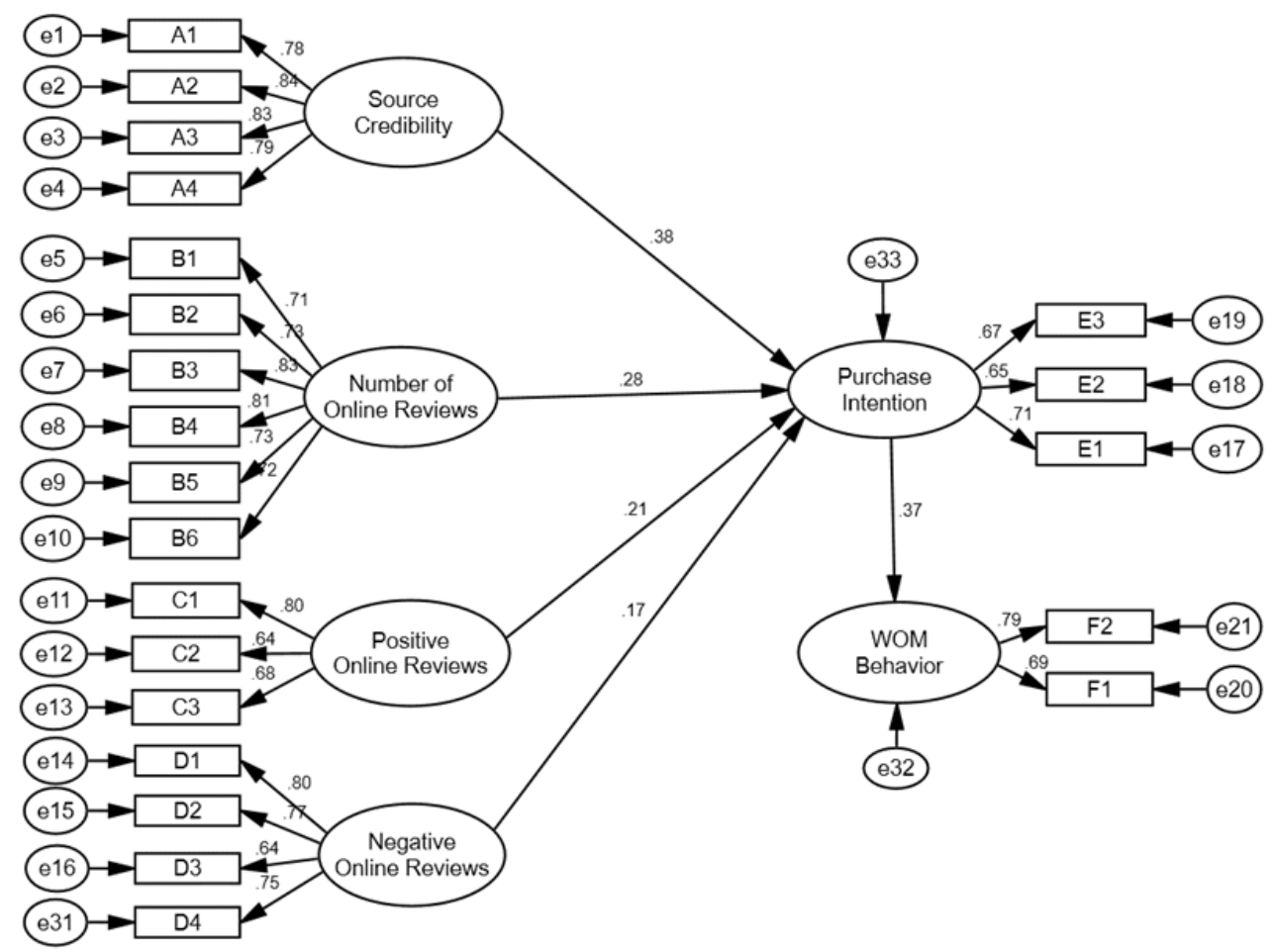

Figure 2. Results of structural equation modelling.

Figure 5 and Table 4 summarized the result of our hypotheses. Source credibility of online reviews positively affects purchase intention $(\beta=0.38, p<.001)$. Number of online reviews positively affects purchase intention $(\beta=0.28, \mathrm{p}<.001)$. Positive online reviews positively affect purchase intention $(\beta=0.21, p<.01)$. Negative online reviews negatively affect purchase intention $(\beta=0.17, p<.05)$. Lastly, Purchase intention significantly affects WOM behavior $(\beta=0.37, p<.001)$.

\section{Table 4}

Maximum likelihood estimates for research model

\begin{tabular}{lccc}
\hline \multicolumn{1}{c}{ Independent Variable } & Dependent Variable & $\begin{array}{c}\text { Standardized } \\
\text { Estimated }\end{array}$ & $p$-value \\
\hline Source credibility & Purchase intention & .38 & $* * *$ \\
Number of online reviews & Purchase intention & .28 & $* * *$ \\
Positive online reviews & Purchase intention & .21 & $* *$ \\
Negative online reviews & Purchase intention & .17 & $*$ \\
Purchase intention & WOM behavior & .37 & $* * *$ \\
\hline Note. $* p<.05 ; \quad * * p<.01 ; * * * p<.001$. & & &
\end{tabular}




\section{Discussion and Conclusion}

Online review plays an important role in setting consumer intention and their purchase making decisions based on consumer awareness of information source (Dellarocas, Gao, \& Narayan, 2010). Getting deep knowledge of the effects of online reviews helps online marketers optimize eWOM in order to adopt an effective marketing strategy on online retailing. Not like most of previous research on the effect of online review in terms of either an information channel or review content itself, the current study extends a more comprehensive effect by evolving the features of both online review and reviewer related factors. The current findings imply that the impacts of online reviews on purchase intention depend on three features, including source credibility, number of online reviews, and valence of online reviews.

In more details, as for source credibility, the current result is consistent with previous findings that the review expertise is crucial when purchase decisions are made (White, 2005). And it is found that source credibility effect is more important than others in predicting consumer purchase intention. In addition, valence of online reviews significantly influences people's purchase intentions. This finding extends previous studies suggesting that the more positive valence of a review is, the more likely consumers are to purchase the product (Willemsen, Neijens, Bronner, \& Ridder, 2011). In order to figure out the inconsistent effects of review valence, in this research, positive reviews are found to be more effective than negative ones and this is consistent with results of Zhao et al. (2014). Also, this study illustrates the positive impacts of number of online reviews on purchase intention. Due to the development of technologies and online retailing platforms, there are more and more valuable online reviews from anonymous reviewers. At the same time, the more information of product/service is revealed, the more it enhances consumer awareness related to product/service, a key variable in explaining consumer choice, which will motivate their final decisions (Vermeulen \& Seegers, 2009). Thus it evokes the fact of increasing the number of online reviews about a product posted on e-commerce websites or virtual communities.

Besides, most research treats eWOM as an exogenous factor and discusses how this exogenous would affect sales, but rarely considers and investigates eWOM as also an outcome of sales, in other words, investigate to what extent the exogenous variable influences on the endogenous variable. Thus this study examines whether consumer purchase intention of a product/service influences the WOM of consumers. Support for this finding is in evidence by Duan, Gu, and Whinston (2008) and Mahajan, Muller, and Wind (2000) that the number of consumers is positively related to the distribution of eWOM. In this study, it shows a strong effect that the more likely consumers are to purchase a product, the more they may want to share positive opinions or recommend the product to others, especially their friends, family, and many others.

\subsection{Managerial Implication}

The findings can increase online retailers' understanding of the role that online reviews play in a stage of purchase decision making process. The results of this study can be used by online retailers to adopt the strategies containing more valuable online reviews and take advantage of those on popular e-commerce platforms such as Amazon. In spite of negative influences of negative reviews on purchase intentions, online marketers as well as retailers are able to somehow control or decrease those kinds of effects. Such as, it is shown that positive reviews produce a greater effect than negative ones in conjunction with the increasingly positive effect of number of online reviews on consumer behavior. It can facilitate the cover of the unexpected results of negativity on consumers. Managers should focus on managing online reviews on e-retailer platforms because it plays a major role in their marketing success. As results indicated that three characteristics of online reviews can enhance purchase intention which motivates consumers to share information related to the product, and marketers should pay more attentions to develop a strategy regarding to online reviews on online retailing platforms which can make a good result on sales.

Overall, this paper contributes to literature by proposing a conceptualization of WOM behavior, which is 
The influence of online reviews on word of mouth behavior through consumer purchase intention in e-commerce motivated by online reviews, a form of eWOM. In practice, with exposure to a product/service by reading related online reviews, one can share information online or offline to others. And this effect may be stronger if the purchase decision was made before, not only the intention; further research may investigate the same relationship by adopting another mediating variable - consumer purchase decision - for a clearer result.

\subsection{Limitation and Future research}

There are some limitations and suggestions for future research. First, the sample in this study focuses on Vietnamese consumers only; thus, the result may not be consistent with that for other countries. Future research may consider other countries' samples and compare different cultural effects. Second, several contextual and individual difference variables could affect the relationships proposed in our model. Future research could consider the moderating effect of age and other individual variables on purchase intention and WOM behavior. A third limitation is that we only consider Amazon as a commercial website; however, different platforms involve different functional communication and participants. Further study could include other platforms to investigate consumers' behavior.

\section{References}

Chevalier, J. A., \& Mayzlin, D. (2006). The effect of word of mouth on sales: online book reviews. Journal of Marketing Research, 43(3), 345-354. https://doi.org/10.1509/jmkr.43.3.345

Davis, A., \& Khazanchi, D. (2008). An empirical study of online word of mouth as a predictor for multi-product category e-commerce sales. Electronic Markets, 18(2), 130-141. https://doi.org/10.1080/10196780802044776

Dellarocas, C., Gao, G. G., \& Narayan, R. (2010). Are consumers more likely to contribute online reviews for hit or niche products? Journal of Management Information Systems, 27(3), 127-158. https://doi.org/10.2753/MIS0742-1222270204

Duan, W., Gu, B., \& Whinston, A. B. (2008). The dynamics of online word-of-mouth and product sales: An empirical investigation of the movie industry, Journal of Retailing, 84(2), 233-242. https://doi.org/10.1016/i.jretai.2008.04.005

Duffy, M., \& Thorson, E. (2008). Emerging trends in the new media landscape and their impact on health communication. In J. Parker \& E. Thorson (Eds.), Health care communication in the new media landscape (pp. 93-116). New York: Springer.

Elliott, K. M. (2002), Understanding consumer-to-consumer influence on the web. Durham: Duke University.

Fornell, C., \& Larcker, D. F. (1981). Structural equation models with unobservable variables and measurement error. Journal of Marketing Research, 18(1), 39-50. https://doi.org/10.1177/002224378101800104

Gavilan, D., Avello, M., \& Martinez-Navarro, G. (2018). The influence of online ratings and reviews on hotel booking consideration. Tourism Management, 66, 53-61. https://doi.org/10.1016/j.tourman.2017.10.018

Hair, J. F., Black, W. C., Babin, B. J., \& Anderson, R. E. (2010). Multivariate data analysis (7th ed.). New Jersey: Prentice-Hall.

Hart, C. W., Heskett, J. L., \& Sasser, W. E. Jr. (1990). The profitable art of service recovery. Harvard Business Review, 68(4), 148-156.

Hong, H., Xu, D., Wang, G. A., \& Fan, W. (2017). Understanding the determinants of online review helpfulness: A meta-analytic investigation. Decision Support Systems, 102, 1-11. https://doi.org/10.1016/j.dss.2017.06.007

Keyes, 2018. Amazon is entering Vietnam. Retrieved from http://www.businessinsider.com/amazon-to-enter-vietnam-2018-3

KPMG, 2017. Online shopping seen booming in Vietnam. Retrieved from https://home.kpmg.com/vn/en/home/insights/2017/01/online-shopping-seen-booming-in-vietnam.html

Kunja, S. R., \& GVRK, A. (2018). Examining the effect of eWOM on the customer purchase intention through value co-creation (VCC) in social networking sites (SNSs). A study of select Facebook fan pages of 
Le, K. H., \& Luong, D. B.

smartphone brands in India. Management Research Review. https://doi.org/10.1108/MRR-04-2017-0128

Lachlan, K. A., Spence, P. R., Lin, X., Del Greco, M., \& Najarian, K. (2014). Twitter use during a weather event: Comparing content associated with localized and non-localized hashtags. Communication Studies, 65, 519-534. https://doi.org/10.1080/10510974.2014.956940

Lee, J., Park, D., \& Han, I. (2008). The effect of negative online consumer reviews on product attitude: an information processing view. Electronic Commerce Research and Applications, 7(3), 341-352. https://doi.org/10.1016/j.elerap.2007.05.004

Lee, S., \& Choeh, J. Y. (2017). Exploring the determinants of and predicting the helpfulness of online user reviews using decision trees. Management Decision, 55(4), 681-700. https://doi.org/10.1108/MD-06-2016-0398

Lin, X., Spence, P. R., \& Lachlan, K. A. (2016). Social media and credibility indicators: The effect of influence cues. Computers in Human Behavior, 63, 264-271. https://doi.org/10.1016/j.chb.2016.05.002

Liu, Y. (2006). Word of mouth for movies: its dynamics and impact on box office revenue. Journal of Marketing, 70(3), 74-89. https://doi.org/10.1509/jmkg.70.3.074

Liu, Z., \& Park, S. (2015). What makes a useful online review? Implication for travel product websites. Tourism Management, 47, 140-151. https://doi.org/10.1016/j.tourman.2014.09.020

Mahajan, V., Muller, E., \& Wind, Y. (2000). New-product diffusion models. Boston, MA: Kluwer Academic Publishers.

Mudambi, S. M., \& Schuff, D. (2010). What makes a helpful online review? A study of customer reviews on Amazon.com. MIS Quarterly, 34(1), 185-200. https://doi.org/10.2307/20721420

Pornpitakpan, C. (2004). The persuasiveness of source credibility: a critical review of five decades' evidence. Journal of Applied Social Psychology, 34(2), 243-281. https://doi.org/10.1111/j.1559-1816.2004.tb02547.x

Racherla, P., \& Friske, W. (2012). Perceived 'usefulness' of online consumer reviews: An exploratory investigation across three services categories. Electronic Commerce Research and Applications, 11, 548-559. https://doi.org/10.1016/j.elerap.2012.06.003

Ratzan, S. C. (2011). Our new social communication age in health. Journal of Health Communication, 16(8), 803-804. https://doi.org/10.1080/10810730.2011.610220

ShareThis. (2014). The return on a share: Quantifying the monetary value of social sharing. Retrieved from https://www.beresfordresearch.com/The_Return_On_A_Share.pdf

Sichtmann, C. (2007). An analysis of antecedents and consequences of trust in a corporate brand. European Journal of Marketing, 41(9), 999-1015. https://doi.org/10.1108/03090560710773318

Siering, M., Muntermann, J., \& Rajagopalan, B. (2018). Explaining and predicting online review helpfulness: The role of content and reviewer-related signals. Decision Support Systems, 108, 1-12. https://doi.org/10.1016/j.dss.2018.01.004

Sundar, S. S., Oeldorf-Hirsch, A., \& Xu., Q. (2008). The bandwagon effect of collaborative filtering technology. Proceedings of the 2008 Conference on Human Factors in Computing Systems, 2, 3453-3458. https://doi.org/10.1145/1358628.1358873

Sundaram, D. S., Mitra, K., \& Webster, C. (1998). Word-of- mouth communications: a motivational analysis. Advances in Consumer Research, 25(1), 527-531.

Tsao, W. C., Hsieh, M. T., Shih, L. W., \& Lin, T. M. (2015). Compliance with eWOM: the influence of hotel reviews on booking intention from the perspective of consumer conformity. International Journal of Hospitality Management, 46, 99-111. https://doi.org/10.1016/j.ijhm.2015.01.008

Vermeulen, I. E., \& Seegers, D. (2009). Tried and tested: the impact of online hotel reviews on consumer consideration. Tourism Management, 30(1), 123-127. https://doi.org/10.1016/j.tourman.2008.04.008

VnExpress, 2017. Vietnamese prefer overseas sites for online shopping, new report says. Retrieved from https://e.vnexpress.net/news/business/vietnamese-prefer-overseas-sites-for-online-shopping-new-reportsays-3546799.html

Vogel, T., Bohner, G., \& Wanke, M. (2014). Attitudes and attitude change. Hoboken, NJ: Taylor and Francis. 
The influence of online reviews on word of mouth behavior through consumer purchase intention in e-commerce

Wangenheim, F. V., \& Bayón, T. (2003). The effect of word of mouth on services switching: measurement and moderating variables. European Journal of Marketing, 38, 1173-1195. https://doi.org/10.1108/03090560410548924

White, T. B. (2005). Consumer trust and advice acceptance: The moderating roles of benevolence, expertise, and negative emotions. Journal of Consumer Psychology, 15, 141-148. https://doi.org/10.1207/s15327663jcp1502_6

Willemsen, L. M., Neijens, P. C., Bronner, F., \& Ridder, J. A. (2011). Highly recommended! The content characteristics and perceived usefulness of online consumer reviews. Journal of Computer-Mediated Communication, 17, 19-38. https://doi.org/10.1111/j.1083-6101.2011.01551.x

Wirtz, J., \& Chew, P. (2002). The effects of incentives, deal proneness, satisfaction and tie strength on word-of-mouth behavior. International Journal of Service Industry Management, 13(2), 141-62. https://doi.org/10.1108/09564230210425340

Wu, T. Y., \& Lin, C. A. (2017). Predicting the effects of eWOM and online branding messaging: Source trust, bandwagon effect and innovation adoption factors. Telematics and Informatics, 34, 470-480. https://doi.org/10.1016/j.tele.2016.08.001

Zhang, K. Z. K., Zhao, S. J., Cheung, C. M. K., \& Lee, M. K. O (2014). Examining the influence of online reviews on consumers' decision-making: A heuristic-systematic model. Decision Support Systems, 67, 78-89. https://doi.org/10.1016/j.dss.2014.08.005

Zhang, W., \& Watts, S. (2008). Capitalizing on content: information adoption in two online communities. Journal of the Association for Information Systems, 9(2), 73-94. https://doi.org/10.17705/1jais.00149

Zhao, X., Wang, L., Guo, X., \& Law, R. (2014). The influence of online reviews to hotel booking intentions. International Journal of Contemporary Hospitality Management, 27(6), 1343-1364. https://doi.org/10.1108/IJCHM-12-2013-0542

Zou, P., Yu, B., \& Hao, Y. (2011). Does the valence of online consumer reviews matter for consumer decision making? The moderating role of consumer expertise. Journal of Computers, 6(3), 484-488. https://doi.org/10.4304/jcp.6.3.484-488 
Le, K. H., \& Luong, D. B. 